See Article page 1546.

\section{Commentary: Peripheral cannulation for postcardiotomy extracorporeal life support: An important piece of a much larger puzzle}

\author{
Hellmuth R. Muller Moran, MD, ${ }^{\mathrm{a}, \mathrm{b}}$ and \\ Rakesh C. Arora, MD, PhD, FRCSC ${ }^{\mathrm{a}, \mathrm{b}}$
}

Postcardiotomy extracorporeal life support (PC-ECLS) is an essential component of contemporary cardiac surgical care. Temporary PC-ECLS can permit recovery of native myocardial or pulmonary function, correction of underlying derangements precluding the same, or allow time for bridging to more durable forms of support, as needed. The recent seminal European Association for CardioThoracic Surgery, the Extracorporeal Life Support Organization, the Society of Thoracic Surgeons, and the American Association for Thoracic Surgery expert consensus statement provided recommendations on several aspects for PC-ECLS; however, detailed discussion of cannulation strategies was less granular in detail. ${ }^{1}$

The study by Schaefer and colleagues ${ }^{2}$ reinforces much of what is known about PC-ECLS. ${ }^{2}$ Femoral cannulation is suitable for most patients and can be completed quickly even under emergency circumstances, although with the downside of potential limitations in patient mobility. ${ }^{1}$ Further, this approach has been associated with limb ischemia, which may be mitigated by the introduction of a distal perfusion cannula. ${ }^{1}$ Although the latter finding did

\footnotetext{
From the ${ }^{\mathrm{a} D i v i s i o n}$ of Cardiac Surgery, Department of Surgery, Max Rady College of Medicine, University of Manitoba, Winnipeg, Manitoba, Canada; and ${ }^{\mathrm{b}}$ Cardiac Sciences Program, St Boniface Hospital, Winnipeg, Manitoba, Canada.

Disclosures: Dr Arora has an unrestricted grant from Pfizer Canada Inc, and has received honoraria from Abbott Nutrition, Edwards Lifesciences, and AVIR Pharmaceuticals for work unrelated to this article. The other author reported no conflicts of interest.

The Journal policy requires editors and reviewers to disclose conflicts of interest and to decline handling or reviewing manuscripts for which they may have a conflict of interest. The editors and reviewers of this article have no conflicts of interest.

Received for publication Oct 3, 2021; revisions received Oct 3, 2021; accepted for publication Oct 4, 2021; available ahead of print Oct 7, 2021.

Address for reprints: Rakesh C. Arora, MD, PhD, FRCSC, I.H. Asper Clinical Research Institute, CR3015, 369 Tache Ave, Winnipeg, Manitoba, Canada R2H 2A6 (E-mail: rakeshcarora@gmail.com).

J Thorac Cardiovasc Surg 2022;164:1559-60

$0022-5223 / \$ 36.00$

Copyright (c) 2021 by The American Association for Thoracic Surgery

https://doi.org/10.1016/j.jtcvs.2021.10.003
}

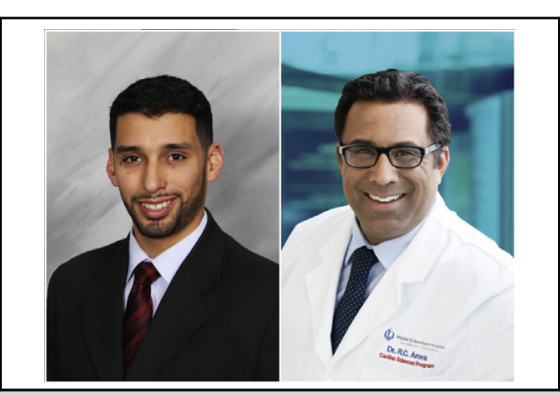

Hellmuth R. Muller Moran, MD, and Rakesh C. Arora, MD, PhD, FRCSC

\section{CENTRAL MESSAGE}

Axillary cannulation for postcardiotomy extracorporeal life support may be associated with greater rates of stroke, although definitive, prospective data are required to properly test this association.

not reach statistical significance in this analysis, the authors admit that the study was likely underpowered to detect such a difference. Axillary cannulation is more frequently undertaken in the operating room and may permit better patient mobilization. ${ }^{1}$ The axillary approach, however, has been associated with greater rates of ipsilateral arm hyperperfusion and especially cannulation site bleeding (represented by cannulation site revision in this analysis).

An important novel observation in the analysis by Schaefer and colleagues, ${ }^{2}$ is the finding of an increased stroke rate after axillary artery cannulation. Whereas cerebral vascular events during axillary cannulation have been suggested in previous smaller cohort studies, ${ }^{3}$ other reports have been conflicting. ${ }^{4}$ The observed finding that the majority of strokes were radiographically documented as right hemispheric supports the right axillary site as contributory, although important differences between patients who underwent axillary versus femoral cannulation cannot be discounted. The numerous baseline and procedural characteristics known to be associated with postoperative strokewhich were more prevalent in the axillary cannulation group - make it difficult to attribute these findings entirely to cannulation strategy despite the statistical analysis that was performed. We agree with the authors that this critical 
question is unlikely to be resolved through retrospective analyses and that a multicenter, randomized controlled trial comparing ECLS strategies is warranted.

Deciding which cannulation site to use is clearly a vital node in the care of ECLS patients. At the same time, many more aspects of ECLS care remain unstandardized, particularly in postoperative settings. Consider the multitude of available modalities ${ }^{1}$ that may permit earlier recognition and therefore rescue ${ }^{5}$ from potentially disastrous consequences. These may additionally guide decision making such as by ensuring adequate cerebral oxygenation, optimizing hemodynamic parameters, managing bleeding and thrombotic complications, determining suitability for weaning, and also establishing futility. It is compulsory for teams charged with the care of ECLS patients to remain informed on the relative risks and benefits of commonly used ECLS configurations at their center and to leverage the availability of advanced modalities to best serve their patients' needs. In the future, standardized data collection on complications, including documentation of neurologic scoring, will be of paramount importance to determine optimal strategies for the management of patients requiring ECLS.

\section{References}

1. Lorusso R, Whitman G, Milojevic M, Raffa G, McMullan DM, Boeken U, et al. 2020 EACTS/ELSO/STS/AATS expert consensus on post-cardiotomy extracorporeal life support in adult patients. J Thorac Cardiovasc Surg. 2021;161:1287-331. https://doi.org/10.1016/j.jtcvs.2020.09.045

2. Schaefer A-K, Distelmaier K, Riebandt J, Goliasch G, Bernardi MH, Zimpfer D, et al. Access site complications of postcardiotomy extracorporeal life support. $J$ Thorac Cardiovasc Surg. 2022;164:1546-58.e8.

3. Ranney DN, Benrashid E, Meza JM, Keenan JE, Bonadonna DK, Bartz R, et al. Central cannulation as a viable alternative to peripheral cannulation in extracorporeal membrane oxygenation. Semin Thorac Cardiovasc Surg. 2017;29:188-95. https://doi.org/10.1053/j.semtcvs.2017.02.007

4. Chamogeorgakis T, Lima B, Shafii AE, Nagpal D, Pokersnik JA, Navia JL, et al. Outcomes of axillary artery side graft cannulation for extracorporeal membrane oxygenation. $J$ Thorac Cardiovasc Surg. 2013;145:1088-92. https: //doi.org/10.1016/j.jtcvs.2012.08.070

5. Reddy HG, Shih T, Englesbe MJ, Shannon FL, Theurer PF, Herbert MA, et al. Analyzing "failure to rescue": is this an opportunity for outcome improvement in cardiac surgery? Ann Thorac Surg. 2013;95:1976-81. https://doi.org/10.1016/ j.athoracsur.2013.03.027 